\title{
Corte Suprema de Justicia de la Nación
}

Causa: T., X. H., en rep. U. E.G. T.T. c/ Obra Social del Poder Judicial de la Nación s/ leyes especiales (diabetes, cáncer, fertilidad).

Buenos Aires, 14 de agosto de 2018

Vistos los autos: "Recurso de hecho deducido por la deman $\neg$ dada en la causa T., I. H./ en rep. U. E.G. T.T. c/ Obra Social del Poder Judicial de la Nación s/ leyes especiales (diabetes, cáncer, fertilidad)", para decidir sobre su procedencia.

Considerando:

$1^{\circ}$ ) Que la Sala II de la Cámara Federal de Apelacio $\neg$ nes de San Martin revocó la sentencia de la instancia anterior y, en consecuencia, hizo lugar a la acción de amparo entablada por I.H.T. para que la Obra Social del Poder Judicial de la Naᄀción cubra en su totalidad el costo que.irroga la participación de su hijo menor en el proyecto deportivo especial "Despertar" que se desarrolla en el Club Social y Deportivo El Progreso (Club* Estudiantil Porteño) de Ramos Mejia, Partido de La Matan $\neg$ za, Provincia de Buenos Aires.

$2^{\circ}$ ) Que para decidir,, del modo indicado el a quo in $\neg$ vocó, además de las previsiones contempladas en la Constitución Nacional y las garantías establecidas en tratados internaciona $\neg$ les en materia de derechos humanos (especialmente los que hacen foco en la protección.del niño y de las personas con discapaci-_dad), las disposiciones de la ley 26.061 (de Protección Integral de los Derechos de las Niñas, Niños y Adolescentes) y las conte $\neg$ nidas en las leyes 22.431 y 24.901 (Sistema de Protección Inte $\neg$ gral de los Discapacitados).

\section{EN TORNO AL ALCANCE DE LAS PRESTACIONES DE SA- LUD QUE BRINDAN LAS OBRAS SOCIALES A PERSONAS CON DISCAPACIDAD DENTRO DEL MARCO DE LA LEGIS- LACIÓN NACIONAL E INTERNACIONAL}

\author{
ON THE SCOPE OF HEALTH BENEFITS PROVIDED BY SOCIAL WORKS TO \\ PEOPLE WITH DISABILITIES WITHIN THE FRAMEWORK OF NATIONAL AND \\ INTERNATIONAL LEGISLATION
}

VALENTINA RUIZ DE LOS LLANOS

\section{RESUMEN:}

El presente trabajo, tiene por finalidad el análisis de un nuevo fallo de la Corte Suprema de Justicia de la Nación, referido a los alcances de las prestaciones en materia de salud que las Obras Sociales deben brindar a las personas con discapacidad y qué debe entenderse por cobertura integral

\footnotetext{
1 Abogada (Universidad Nacional de Tucumán), Juez Civil en Documentos y Locaciones IXº Nominación, Centro Judicial Capital, Pcia. de Tucumán, Magister en Magistratura y Gestión Judicial (Universidad del Norte Santo Tomás de Aquino). Correo electrónico: valenacosta@hotmail.com - ORCID iD: https://orcid.org/0000-0001-9994-1625.
} 
Sobre la base del principio de que la persona que su $\neg$ fre discapacidad tiene derecho al disfrute del más alto nivel posible de salud y de servicios para el tratamiento de su enfer $\neg$ medad y su rehabilitación, la cámara valoró los informes socio- ambientales incorporados a la causa que daban cuenta, por un la $\neg$ do, del contexto de pobreza del hogar de la actora y, por otro, de la mejora experimentada por el menor en su integración e in $\neg$ clusión social a raíz de su asistencia al programa deportivo ya referido, como así también sus especiales condiciones de salud (padece, entre otras patologías, de síndrome de Down, cardiopatía e hipotiroidismo).

3o) Que contra dicha decisión la demandada dedujo el recurso extraordinario -cuya denegación origina la presente que $\neg$ ja- en el que alega ser ajena al marco de las leyes 23.660 (de Obras Sociales) y 23.661 (de Seguro de Salud) en el que resulta obligatorio el acatamiento de las disposiciones que implementan el Sistema de Protección de las Personas con Discapacidad. De todos modos, sostiene, ese régimen no obliga a las obras socia $\neg$ les ni a las empresas de medicina prepaga a financiar activida $\neg$ des deportivas o recreativas sino solamente las terapias y tra $\neg$ tamientos brindados por profesionales de la salud en institucio $\neg$ nes inscriptas en el Registro Nacional de Rehabilitación. Afir $\neg$ ma, asimismo, que el lugar al que concurre el menor es un club social que no está categorizado por el Ministerio de Salud ni figura en el registro referido como tampoco lo están las perso $\neg$ nas a cargo del proyecto "Despertar" que no son profesionales de la salud sino docentes de educación física. Plantea que jamás se ha desentendido de la especial situación del menor pues en la actualidad, además de cubrirle en su totalidad la cuota del co $\neg$ legio especial al que asiste, como así también el pertinente transporte, los tratamientos de psicopedagogía y fonoaudiología y los medicamentos que su salud requiere, ofreció a la actora brindarle hidroterapia mediante alguna de las instituciones prestadoras, propuesta que fue rechazada. Explica, por lo demás, que efectuó una excepción a las normas reglamentarias relativas a la atención de los afiliados con discapacidad y homologó al citado proyecto deportivo como centro de día categoría C, jorna $\neg$ da doble, una vez por semana y admitió parcialmente la cobertura bajo esa modalidad.

4o) Que existe en el caso materia federal suficiente que habilita el examen de los agravios por la vía elegida pues se ha puesto en cuestión la interpretación de normas federales y la decisión ha sido contraria al derecho

\section{ABSTRACT:}

The purpose of this work is to analyze a new ruling of the Supreme Court of Justice of the Nation, referring to the scope of health benefits that Social Works must provide to people with disabilities and to analyze what should be understood by comprehensive coverage.

Palabras Claves: Derecho a la salud; Discapacidad; Actividad recreacional; Obras Sociales; Tratados internacionales.

Key Words: Right to Health; Disability; Recreational activity; Social Works; International Deals.

\section{Introducción}

La Constitución Argentina de 1853, no contenía una mención expresa del derecho a la salud, tampoco el Código Civil Velezano contaba con disposiciones específicas sobre esta materia. A partir de la reforma de la Constitución Nacional de 1994, con la inclusión de los Tratados Internacionales con jerarquía superior a las leyes establecida en el art. 75 inc. 22, y que sirvieron de inspiración a las previsiones contenidas en las leyes argentinas en materia de salud, se incorpora de manera explícita a la Carta Magna este derecho.

"Es por esta razón, que las modificaciones introducidas por la Reforma de 1994, delimitaron dos grandes ámbitos: el orden de prelación de las normas y los espacios de integración regional, dado que las nuevas cláusulas contenidas en los dos incisos del art. 75 de la C.N., sobre las atribuciones del Congreso, introducen modificaciones a las disposiciones correlativas a los 
que la apelante fundó en ellas (art. 14 de la ley 48).

$5^{\circ}$ ) Que corresponde, en primer lugar, precisar el marco jurídico de la contienda suscitada en esta causa. Las le ᄀyes 22.4-31 y 24.901, que establecen el Sistema. Único de Prestaciones Básicas para Personas con Discapacidad, obligan a las obras sociales comprendidas bajo la órbita de la ley 23.660 a suministrar los servicios asistenciales especificados en ellas. Ahora bien, no obstante que la Obra Social del Poder Judicial de - la Nación se halla excluida, expresamente del régimen de la ley 23.660 en razón de lo dispuesto por el art. 4o de la ley 23.890, esa entidad, a través de la resolución 1126/2004, se adhirió al referido sistema de prestaciones y reguló el alcance de la aten $\neg$ ción de sus afiliados discapacitados.

$6^{\circ}$ ) Que de las constancias de autos surge que el proᄀyecto "Despertar" consiste en la realización de actividades de $\neg$ portivas, lúdicas y recreativas entre las que se encuentran na $\neg$ tación, tenis, fútbol, etc., que se desarrollan

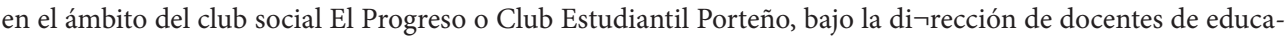
ción física (fs. 135/136, 147/153).

7o) Que la ley 24.901, como advierte la demandada, no contempla entre las prestaciones que las instituciones asistenciales deben cubrir obligatoriamente, la actividad cuyo costo la actora pretende que se le reembolse en su totalidad. Tampoco está incluida en el Programa Médico Obligatorio (P.M.O.) cuyo acatamiento se impone a las obras sociales que integran el sis $\neg$ tema de la ley 23.660 (resolución del Ministerio de Salud 201/2002) pues no se trata de un tratamiento médico asistencial sino de una actividad recreacional o deportiva que excede el marco reglamentario del sistema de protección general de la sa $\neg$ lud y el particular del de las personas con discapacidad. De ahí que la pretensión, en los términos en que ha sido deducida, ca $\neg$ rezca de respaldo legal. En ese sentido, cabe observar que el reclamo de autos no apunta a la cobertura de un servicio tera $\neg$ péutico concreto -sea de rehabilitación, de formación laboral, educativo o asistencial- que se brinde en algún centro de salud, educativo, terapéutico o de rehabilitación psicofísica o motora, sino que se dirige al desarrollo de una actividad de tipo socio- deportiva.

8o) Que la sola circunstancia de que la prestación requerida resulte beneficiosa para el menor, con miras a

arts. 27 y 31 de la CN. El constituyente siguió la corriente que se impone en el derecho constitucional tendiente a la internalización de los derechos humanos." 2

La incorporación de los tratados internacionales al sistema jurídico nacional ha quedado completada con el reconocimiento explícito que de ellos realiza el Código Civil y Comercial de la Nación unificado, incluyendo en varios de sus artículos referencias atinentes a ellos.

En relación a las disposiciones contenidas en los instrumentos de derecho internacional este sentido, “...merece destacarse en primer lugar la Declaración Americana de Derechos y Deberes del Hombre, adoptada en 1948, que en su artículo 11 refiere que toda persona tiene derecho a que su salud sea preservada por medidas sanitarias y sociales, relativas a la alimentación, el vestido, la vivienda y la asistencia médica, correspondientes al nivel que permitan los recursos públicos y los de la comunidad (...) el Pacto Internacional de Derechos Económicos, Sociales y Culturales de las Naciones Unidas obliga a los Estados parte a reconocer el derecho de toda persona al disfrute del más alto nivel posible de salud física y mental, deber que conlleva la adopción de medidas concretas a fin de asegurar la plena efectividad de este derecho, (...) En el ámbito del sistema interamericano, el Pacto de San José de Costa Rica no se ocupó específicamente de la regulación de derechos de naturaleza social, categoría donde se incluyó tradicionalmente al derecho a la salud. Dichas falencias debieron ser completadas por el Protocolo de San Salvador, el cual amplía y actualiza el contenido del Pacto de Naciones Unidas

2 PALACIO DE CAERIO, Silvia B., Tratado de Derechos Humanos y su influencia en el derecho argentino, 1ra ed. Ciudad Autónoma de Buenos Aires, La Ley, 2015. 
su inᄀtegración e inclusión, no justifica la imposición a la entidad prestadora de salud de la obligación de solventarla pues, con el mismo criterio, debería hacerse pesar sobre esta cualquier otra actividad de carácter social que tuviera esa misma finalidad (asistencia a espectáculos públicos o lugares de interés cultu $\neg$ ral, etc.) lo cual carece de toda, razonabilidad y no encuentra basamento normativo alguno. Máxime en este caso en el que, como se señaló anteriormente, la actividad en cuestión no constituye una terapia específica de carácter médico o educativo y los en-cargados de su implementación no son profesionales de la salud o especialistas en el tratamiento y rehabilitación de personas con discapacidad.

9o) Que tampoco da sustento a la procedencia de la prestación perseguida la constatación de una especial situación de vulnerabilidad en el hogar donde vive el menor, en tanto esa condición solo autorizaría a requerir la cobertura necesaria pa $\neg$ ra asegurar la atención especializada domiciliaria que requiera el discapacitado, conforme con la evaluación y orientación efec $\neg$ tuada por un equipo interdisciplinario capacitado a tales efec $\neg$ tos (arts. 11 y 34 de la ley 24.901).

Es correcto que la integración educacional, laboral, familiar y social de la persona que sufre discapacidad constitu $\neg y e$ un principio fundante y orientador del sistema instituido le $\neg$ galmente. Pero también lo es que ni las leyes 22.431 y 24.901 que lo consagran, ni el decreto reglamentario de esta última -1193/98-como tampoco la resolución 428/99 del Ministerio de Salud (nomenclador) exigen la provisión dé prestaciones de índo $\neg l e ~ d e-$ portivo o recreacionales como las reclamadas en la causa por lo que la resolución 1126/2004 de la obra social demandada que adopta idéntico criterio no merece reproche alguno.

$10^{\circ}$ ) Que es pertinente recordar que el Tribunal ha re $\neg$ conocido en reiteradas ocasiones el carácter fundamental del de $\neg$ recho a la salud y la especial atención que merecen las personas con discapacidad. Sin perjuicio de ello, también ha señalado que en nuestro ordenamiento jurídico tales derechos de raigambre constitucional, así como los principios y garantías consagrados en la Constitución Nacional, no son absolutos sino que deben ser desplegados con arreglo a las leyes que reglamentan su ejerci $\neg$ cio, en la forma y extensión que el Congreso, en uso de sus fa $\neg$ cultades propias, lo estime conveniente a fin de asegurar el bienestar general (arts. 14 y 28

al reconocer la salud como un bien público, obligando a los Estados a adoptar medidas para la prevención y el tratamiento de las enfermedades endémicas, profesionales y de otra índole; la educación de la población sobre la prevención y tratamiento de los problemas de salud, y la satisfacción de las necesidades de salud de los grupos de más alto riesgo y que por sus condiciones de pobreza sean más vulnerables. No obstante estos instrumentos universales y regionales, otros tratados de derechos humanos contienen un particular reconocimiento del derecho a la salud y la necesidad de su especial protección en los niños, personas con discapacidad, etcétera”. ${ }^{3}$

A ello corresponde agregar las "100 Reglas de Brasilia sobre acceso a la justicia de personas en condición de vulnerabilidad” (año 2009) y como dijimos, la sanción del nuevo Código Civil y Comercial de la Nación (año 2015) que establece la constitucionalización del derecho privado.

De esta manera, la incorporación de los Tratados Internacionales con jerarquía constitucional, o para algunos autores supraconstitucional, ha venido a incidir en las decisiones judiciales de manera relevante, tal como se verá en el caso que motivó el fallo de la Corte Suprema de Justicia de la Nación dictado en el marco de la causa T., I. H., en rep. U.E.G. T.T C/ Obra Social del Poder Judicial s/ leyes especiales, evidenciando la necesidad de efectuar una ponderación entre éstos y el derecho interno armonizando ambos en la búsqueda de un justo equilibrio.

3 ROSALES, Pablo Oscar, La Discapacidad en el Sistema de Obras Sociales Nacionales, la Emergencia Sanitaria y los derechos de los beneficiarios con discapacidad.(2011) https://es.scribd.com/doc/63600339/Ley-24901-LA-DISCAPACIDAD-EN-EL-SISTEMA-DE-OBRAS-SOCIALES-NACIONALESDr-Pablo-Oscar-Rosales. 
de la Constitución Nacional), con la única condición de no ser alterados en su substancia (Faᄀllos : 257:275; 2 62:205; 283:98; 300:700; 303:1185; 305:831; 310:1045; 311:1132 y 1565; 314:225 y 1376; 315:952 y 1190; $319: 1165 ; 320: 196 ; 321: 3542 ; 322: 215 ; 325: 11$, entre muchos otros).

$11^{\circ}$ ) Que en tal orden de ideas no se advierte que, en este caso, la Obra Social del Poder Judicial de la Nación haya exhibido una conducta arbitraria o ilegítima con respecto a la atención prestacional del menor involucrado. Ello es así pues, lejos de negarle cobertura, ha ofrecido a la actora asumir el costo de actividades alternativas a la requerida pero en el mar $\neg$ co de una prestación médico asistencial organizada, coordinada y dirigida conforme con las pautas que exige el Ministerio de Sa $\neg$ lud (hidroterapia). Y no solo ello, sino que además, aun sin obligación legal y en forma excepcional, le otorgó al programa deportivo en cuestión una homologación equivalente a la de cen $\neg$ tro de día categoría C, jornada doble, una vez por semana (art. 24 de la ley 24.901), a los fines de solventar en parte el costo de la participación del menor.

En tales condiciones, corresponde hacer lugar a la queja, declarar procedente el recurso extraordinario, revocar el fallo recurrido y rechazar la demanda (art. 16 de la ley 48).

Por ello, se hace lugar a la queja, se declara procedente el recurso extraordinario, se revoca la sentencia apelada y se rechaza la demanda. Costas por su orden en atención a la índole de la materia debatida. Agréguese la queja al expediente principal. Notifíquese y remítase.

Recurso de queja interpuesto por el Estado Nacional (Ministerio de Justicia y Derechos Humanos de la Nación), representado por los Dres. Juan Enrique Abre y Cecilia Mabel Ezcurra.

Tribunal de origen: Sala II de la Cámara Federal de Apelaciones de San Martín.

Tribunal que intervino con anterioridad: Juzgado Federal en lo Civil, Comer $\neg$ cial y Contencioso Administrativo $n^{\circ} 1$ de San Martin.

\section{EI caso: sentencias de primera Instancia y de cámara}

La Señora I.H.T, madre de un adolescente con síndrome de Down, solicitó a la Obra Social del Poder Judicial de la Nación de la cual es afiliado, la cobertura de los servicios que brinda el Proyecto Deportivo Especial Despertar consistente en educación física especial con natación correctiva y acompañamiento personalizado a cargo de profesores de Educación Física, a fin de que su hijo asista una vez por semana durante el período lectivo y cinco veces por semana durante los recesos por vacaciones tanto de invierno como de verano.

La Obra Social accedió parcialmente al requerimiento para lo cual homologó a la institución como centro de día categoría C, autorizando la cobertura para la concurrencia del adolescente una vez por semana. Ello motivó el reclamo de la requirente por no contemplar la totalidad del presupuesto presentado, a lo que la Obra Social respondió que el Proyecto Deportivo Despertar no se encuentra amparado por la Resolución Ministerial vigente, no obstante lo cual, y de manera excepcional, se lo homologó con el alcance antes descripto para que pueda concurrir una vez por semana. No conforme con lo decidido en el expediente administrativo, la Sra. I.H.T., interpuso acción de amparo y medida cautelar para obtener el 100\% de la cobertura de la asistencia de su hijo al centro especial.

La sentencia de primera instancia rechazó la medida cautelar, resolución que fue apelada por el Ministerio Público de la Defensa con resultado adverso en la Alzada. A su turno, la sentencia de fondo rechazó la demanda con imposición de costas a la actora. Este decisorio, fue posteriormente revocado por la Cámara Federal de San Martín, Sala 
II que accedió a lo solicitado en la demanda. Para así decidir, la Cámara tuvo en cuenta las disposiciones contenidas en los Tratados de Derechos Humanos, los arts. 1 y 2 del Cód. Civil y Com., la Convención sobre los Derechos de las Personas con Discapacidad (ley 26.378), la Convención sobre los Derechos del Niño, la Protección Integral de los Derechos de las niñas, niños y adolescentes (ley 26.061), el Sistema de Prestaciones básicas y rehabilitación integral a favor de las personas con discapacidad (ley 24.901), y el Sistema de Protección Integral de los Discapacitados (ley 22.431) por considerarlas aplicables al caso. Los pilares sobre los que se asentó este fallo fueron principalmente los principios pro homine, in dubio pro justicia, interés superior del niño, atención integral de las personas discapacitadas y el orden público de los derechos tutelados.

La Obra Social demandada, dedujo Recurso Extraordinario que le fue denegado, originando la queja que fue acogida por la Corte Suprema en el fallo que motiva este artículo y que revocó la decisión de la Alzada con los alcances que más adelante desarrollaremos.

\section{El fallo de la Corte Suprema: su importancia}

En un breve pero conciso fallo, nuestro Supremo Tribunal revocó la sentencia dictada por la Sala II de la Cámara Federal de San Martín. Luego de reseñar los fundamentos del fallo de la Cámara, la Corte delimitó el marco jurídico de la causa, señalando que si bien la Obra Social demandada se encuentra expresamente excluida del régimen de la Ley 23.660, a través de la Resolución 1126/2004 se adhirió al sistema Único de Prestaciones Básicas para Personas con Discapacidad (leyes 22.431 y 24.901) determinando así el marco y alcance de atención a brindar a sus afiliados discapacitados.

Recordemos que la ley 22.431 incluye predominantemente obligaciones a cargo del Estado Nacional y la ley 24.901 establece obligaciones a cargo de las Obras Sociales, la mayoría de aspectos prestacionales y con carácter educativo.

Así, "mientras el art 1 de la ley 22.431 instituye un sistema de protección "integral" de las personas discapacitadas, la ley 24.901 lo menciona como sistemas de "prestaciones básicas de atención integral", aunque al final del artículo se refiere a la "cobertura integral a sus necesidades y requerimientos". El art 1 de la ley 24.901 contempla "acciones de prevención, asistencia, promoción y protección”, ampliando en este sentido las obligaciones de los prestadores a dos áreas no incluidas en la ley anterior: prevención y promoción, resultando la ley 22.431 de corte más asistencialista que preventivo. El art 1 del decreto reglamentario 1193/98 garantiza la "universalidad de la atención de dichas personas (personas con discapacidad)"'4

El argumento medular del fallo de la Corte residió en que, si bien no se desconoce que "...la integración educacional, laboral, familiar y social de la persona que sufre discapacidad constituye un principio fundante y orientador del sistema instituido legalmente..." y aun cuando la prestación podría resultar beneficiosa para el adolescente, ni las leyes 22.431 y 24.901 (Decreto Reglamentario 1193/98) ni la Resolución MS 428/99 “... exigen la provisión de prestaciones de índole deportivo o recreacionales como las reclamadas en la causa" y, por ello, consideró que atento a que las actividades que desarrolla el proyecto Despertar, (recreativas, deportivas etc.) con profesores de educación física, (que no son profesionales de la salud ni especialistas en rehabilitación o tratamiento de personas con discapacidad) exceden el marco reglamentario del sistema de protección de la salud, aun cuando el afiliado sea discapacitado, por no encontrarse previstas en el Programa Médico Obligatorio y que, como consecuencia de ello, la petición de la actora

4 ROSALES, Pablo Oscar, 2011 Op. Cit. Pág. 2 
carece de marco legal.

A modo de cierre, concluyó el fallo recordando que el derecho a la salud y la especial atención que merece la discapacidad, así como la totalidad de los derechos y garantías de raigambre constitucional "...no son absolutos sino que deben ser desplegados con arreglo a las leyes que reglamentan su ejercicio, en la forma y extensión que el Congreso, en uso de sus facultades propias, lo estime conveniente a fin de asegurar el bienestar general (arts. 14 y 20 de la Constitución Nacional) con la única condición de no ser alterados en su substancia".

Y en esa línea, consideró que la Obra Social demandada no exhibió en el caso una conducta arbitraria o ilegítima, ya que, por el contrario, ofreció a la actora cubrir el costo de actividades alternativas a la solicitada pero dentro del marco de una prestación médico asistencial organizada y de manera excepcional, homologando al programa deportivo como centro de día categoría C, cubrir el costo de la asistencia del menor al proyecto Despertar al menos una vez por semana.

\section{La interpretación de los Tratados Internacionales y los derechos contenidos en la Carta Magna}

De lo expuesto surgen dos cuestiones fundamentales. La interpretación de los tratados en consonancia con los límites que tiene todo derecho de raigambre constitucional, y como corolario de ello, en el caso puntual, los límites a las prestaciones de las Obras Sociales a partir de la noción de cobertura integral.

En relación a la primera cuestión, se advierte que para receptar la petición, el fallo de la Cámara Federal de San Martín, como lo dijimos, se basó en las disposiciones atinentes a la materia contenidas en la multiplicidad de tratados internacionales que consideró automáticamente aplicables al caso en virtud de la interpretación que de ellos debe hacerse conforme la Constitución y los arts. 1 y 2 del Código Civil y Comercial, haciendo hincapié en la garantía de protección integral y la progresividad de los derechos de todas las personas y en especial de los niños discapacitados, concluyendo en que correspondía acceder a la petición más allá de las disposiciones legales o de la obligatoriedad o no del tipo de prestación solicitada, agregando que la accionada no acreditó el desequilibrio económico que le ocasionaría brindar tal prestación.

Por su parte, el fallo de la Corte, al revocar la sentencia de la Cámara Federal, pone sobre el tapete la problemática a la que se enfrentan los jueces nacionales en relación a la interpretación y aplicación de las disposiciones contenidas en los Tratados y demás documentos internacionales incorporados a nuestra Constitución como así también, la obligatoriedad y efectos erga omnes de los fallos de la Corte Interamericana de Derechos Humanos y las resoluciones de los organismos que conforman el Sistema Interamericano de Derechos Humanos.

Es notable la influencia que han ejercido en el derecho interno los tribunales internacionales y por ende la aplicación de los tratados y de los pronunciamientos de los órganos del Sistema de Protección Interamericano. Las resoluciones emitidas por la Comisión Interamericana y la Corte Interamericana de Derechos Humanos han influido tanto en el derecho positivo como en el ámbito doméstico. Esto se evidencia claramente en los argumentos del fallo de la Cámara Federal como vimos.

Un sector de la doctrina destaca que a partir del caso "Almonacid Arellano vs. Chile"5 la Corte Interamericana de Derechos Humanos sentó jurisprudencia sobre el control de

5 CIDH: Caso "Almonacid Arellano y Otros c/ Chile" Sentencia del 26 de Setiembre de 2006. http://www.cidh.org/demandas/12.057\%20Almonacid\%20 Arellano\%20Chile\%2011jul2005\%20ESP.pdf 
convencionalidad que deben efectuar los jueces en el ámbito interno de cada país y según lo expresado por la Corte, los jueces internos deben velar porque los efectos de la Convención Americana sobre Derechos Humanos no sean mermados por la aplicación de leyes contrarias a su objeto y fin. El control de convencionalidad debe ser asimismo efectuado respecto del derecho interno frente a todos los tratados y documentos internacionales ratificados por nuestro país. A partir de este fallo, la Corte IDH fue delineando en sentencias posteriores el concepto de control de convencionalidad, ampliándolo progresivamente, a tal punto de sostener que no sólo deben efectuarlo los jueces sino cualquier autoridad administrativa que se encuentre frente a una disposición contraria a la Convención Interamericana de Derechos Humanos y cuya aplicación signifique vulnerar sus postulados.

Conviene liminarmente esclarecer que, en todo sistema jurisdiccional, existe un ámbito de libertad creadora para los jueces que en Latinoamérica tiene la característica de no condicionar las decisiones, desde que son muy pocas las aplicaciones del principio del precedente obligatorio (stare decisis). Esto significa que, cuando un juez debe resolver, aplica su ciencia y conciencia a los hechos que resuelve. Para formar su convicción es preciso desmenuzar con inteligencia la aplicación de normas contenidas en un contexto global, es decir que, debe observar la totalidad del sistema y ordenar para el caso los contenidos, alcances y efectos de cada disposición. Respecto a las decisiones de la Corte IDH no existen dudas sobre la obligatoriedad de respeto y seguimiento cuando ella proviene de la jurisdicción contenciosa, aun cuando sean necesarias efectuar algunas aclaraciones al respecto lo cual excede el ámbito de este trabajo.

Es decir que, si bien nuestro país ha incorporado los Tratados de Derechos Humanos y otros tratados y disposiciones internacionales a la Carta Magna otorgándoles jerarquía Constitucional ello no significa de manera alguna que sus disposiciones sean aplicadas de manera automática a los casos que se presenten y que involucren derechos tutelados por éstos. Entendemos que en su fallo, la Corte, pondera los principios previstos en los documentos internacionales en correspondencia con los contenidos en las leyes aplicables al caso y concluye en que los primeros, no se ven afectados por los segundos en el caso concreto sometido a decisión, ya que no se observa que haya existido conculcación por parte de la demandada al derecho a disfrutar del más alto nivel de salud por parte del afiliado toda vez que se encuentra acreditado que le brinda la cobertura necesaria para el tratamiento de su enfermedad y rehabilitación en su totalidad y que además, sin obligación legal, le otorgó la cobertura de la asistencia al centro recreacional una vez por semana.

Este análisis de la Corte culmina en la segunda cuestión a la que nos referimos ut supra, en tanto que los derechos y garantías contenidos en nuestra Constitución no son absolutos si no que deben ser desplegados conforme a las leyes que reglamentan su ejercicio en aras de asegurar el bienestar general. De esta manera, el Supremo Tribunal pone el énfasis en que la actividad que desarrolla el proyecto Despertar cuya participación del menor se pretende a cargo de la Obra Social, no consiste en un tratamiento médico asistencial contemplado en la ley 24.901 ni incluida en el PMO, si no que se trata de una actividad recreacional y por tanto no puede considerársela dentro de las prestaciones a cargo de la Obra Social del Poder Judicial, ya que admitirlo, conduciría al absurdo de tener que solventar los gastos que demande cualquier actividad de tipo social con finalidad de recreación que los afiliados quieran realizar.

\section{La actividad recreacional y deportiva en caso de personas con discapacidad, cin- tegra la cobertura de las prestaciones de salud?}


La noción de cobertura integral se refiere a la atención de la multiplicidad de requerimientos que comprende el postulado del pleno disfrute del derecho a la salud y que se encuentran contenidas tanto en las leyes de derecho interno referidas a esta materia como en los tratados y demás documentos internacionales que lo contemplan.

En cuanto a la discapacidad, ésta se trata de desigualdades naturales entre las personas puesto que han nacido con alguna limitación de cualquier tipo sea física y/o mental, o bien que, sin ser de nacimiento, la han adquirido en algún momento del transcurso de sus vidas, diferencias que deben ser compensadas a través de la adopción de medidas positivas que les permitan desenvolverse con dignidad otorgándoles una protección especial.

Siguiendo a Rosales, tenemos que las prestaciones básicas contenidas en la Ley 24.901 pueden resumirse de la siguiente manera:

A) El Capítulo IV de la ley (artículos 14 a 18) titulado "Prestaciones Básicas" (que por otra parte sin duda exceden la definición de básicas) determina cinco tipos de prestaciones: a) preventivas, b) de rehabilitación, c) terapéuticas educativas, d) educativas y, e) asistenciales. B) El capítulo $V$ de la ley (artículos 19 a 28) titulado "Servicios Específicos". Estos servicios son personales del discapacitado a diferencia de los del capítulo siguiente que incluyen al grupo familiar. Como primera norma, la ley establece en su artículo 19 que la enumeración de servicios es meramente enunciativa, pudiendo ser ampliados según algunos criterios concretos (edad, situación socio-familiar, etc.), que fueron reglamentados por la resolución 400/99 para el sistema de Obras Sociales. En forma resumida, estos servicios específicos incluyen: a) Estimulación temprana: para promover el desarrollo del niño con discapacidad. b) Educación inicial: Incluye la primera etapa de la escolaridad, entre los 3 y los 6 años, en escolaridad común o especial, si es posible. c) Educación general básica: Se desarrolla entre los 6 y los 14 años o hasta la finalización del ciclo, dentro de un servicio especial o común. d) Formación laboral: Su finalidad es la preparación adecuada de la persona con discapacidad para la inserción en el mundo laboral. e) Centro de día: Es un servicio que se brindará al niño, joven o adulto con discapacidad severa o profunda, con el objeto de posibilitar el más adecuado desempeño en su vida cotidiana. f) Centro educativo terapéutico: Este servicio tiene como objetivo la incorporación de conocimiento y aprendizaje de carácter educativo a través de enfoques, metodologías y técnicas de carácter terapéutico y está dirigido a niños y joven cuya discapacidad motriz, sensorial y mental, no les permita acceder a un sistema de educación especial sistemático y requieren este tipo de servicios para realizar un proceso educativo adecuado a sus posibilidades. g) Centro de rehabilitación psicofísica: El objeto es la estimulación de las capacidades remanentes de la persona con discapacidad través de rehabilitación en un centro especializado. h) Rehabilitación motora: Este servicio tiene por finalidad la prevención, diagnóstico y tratamiento de las enfermedades discapacitantes de orden predominantemente motriz (...) i) Atención odontológica integral: que abarcará desde atención primaria hasta técnicas quirúrgicas complejas y de rehabilitación. ${ }^{6}$

Como lo hemos señalado, el fallo de la Corte consideró que las actividades deportivas, lúdicas y recreativas no se encuentran incluidas dentro de las prescripciones de la ley 24.901 ni en el Programa Médico Obligatorio, estableciendo de esta manera una limitación a la cobertura por parte de la Obra Social demandada referida a este aspecto, aun cuando como en el caso, el desarrollo de tales actividades puedan ser beneficiosas para el adolescente discapacitado, y sin que ello signifique desatender a la circunstancia 
de especial vulnerabilidad configurada por el tipo de hogar en que aquél vive, lo que no resulta suficiente a criterio de la Corte, para imponer a la entidad la obligación de solventarlas.

"En definitiva, si bien la ley habla de cobertura integral, en la práctica, determinar el alcance de las prestaciones a brindar por las distintas entidades, se hace en cada caso concreto en base al parámetro axiológico de la racionalidad"?

\section{Conclusiones}

Si bien la normativa interna debe adecuarse a la normativa internacional, conforme a los compromisos asumidos por nuestro país al ratificar los tratados internacionales, los derechos de raigambre constitucional o si se quiere supra constitucional, no son absolutos, sino que deben desplegarse conforme a las leyes que reglamentan su ejercicio como reiteradamente lo ha puesto de manifiesto la Corte Suprema, (fallos: 257:275; 262:205; 283:98; 300:1185; 305:831; 311:1132; 314:225, 315:952; 319:1165 y muchos otros precedentes citados en el fallo objeto de comentario).

"Analizar o intentar analizar los límites de los derechos fundamentales representa en buena medida abordar el problema de la fuerza vinculante de los enunciados constitucionales, toda vez que, consagrados éstos por el texto constitucional, cabe preguntarse en qué medida es admisible introducir limitaciones en posiciones subjetivas que han sido proclamadas al máximo nivel normativo, más aún si, como ha quedado antes indicado en frase ya tópica, tales derechos condensan los supremos valores de la comunidad."”

Frente a estos derechos, regular su ejercicio en cada caso particular significa que, en aras de ellos no se vea menoscabado el bienestar general ni que tales derechos sean alterados en su substancia. Particular importancia reviste el principio de razonabilidad y respetar el contenido esencial del derecho en cuestión, para que, adecuado éste a sus justos límites, no se vea de esta manera menoscabado. En el caso puntual que comentamos, la Corte denegó la petición de la actora, para lo cual efectuó un correcto análisis, a partir de la normativa aplicable y, teniendo en cuenta la totalidad de las prestaciones que la Obra Social demandada se encontraba brindando al menor discapacitado concluyó que en atención a éstas, no podía exigírsele solventar la nueva actividad requerida al ser de carácter recreacional y no médica o de rehabilitación. De allí que, con argumentos magistralmente sintetizados, precisos y concisos, el fallo resulta respetuoso del derecho a la salud y de manera alguna altera su substancia. Es que, siempre que se limite un derecho constitucional en consonancia con el art. 14 de la Carta Magna, debe existir una fundamentación adecuada la que se observa en el caso.

"Por otra parte, conviene recordar que los principales textos supranacionales que contienen declaraciones de derechos y respecto a los que no parece que se pueda dudar acerca de su vocación garantista, también contemplan la posibilidad de que los derechos humanos puedan hallarse sometidos a límites. Así, el artículo 29.2 de la Declaración de la ONU señala que en el ejercicio de sus derechos y en el disfrute de sus libertades toda persona estará solamente sujeta a las limitaciones establecidas por la ley, con el único fin

\footnotetext{
7 GÁZQUEZ, María Yanina, "El principio de razonabilidad en la cobertura de las prestaciones de salud", Revista Derecho y Salud UBP, https://revistas.ubp. edu.ar/index.php/rdys/article/view/48.

8 AGUIAR DE LUQUE, Luis. "Límites de los Derechos Fundamentales" (1993) Tomado de https://dialnet.unirioja.es/descarga/articulo/1051173.pdf “31.07.2019".
} 
de asegurar el reconocimiento y respeto de los derechos y libertades de los demás, y de satisfacer las justas exigencias de la moral, del orden público y del bienestar general en una sociedad democrática". 9

Para finalizar, resulta adecuado destacar que en nuestro país, el derecho a la salud se halla correctamente tutelado, tanto constitucionalmente luego de la reforma de 1994 como en el Código Civil y Comercial que en varios artículos contempla este derecho y la dignidad de la persona humana, sumado a las numerosas leyes específicas sobre la materia y merced a la labor jurisprudencial que ha ido plasmándose en la sentencias.

\section{REFERENCIAS BIBLIOGRÁFICAS}

- AGUIAR DE LUQUE, Luis (1993): “Límites de los Derechos Fundamentales”,.

- CIDH: Caso "Almonacid Arellano y Otros c/ Chile" Sentencia del 26 de Setiembre de 2006. http://www.cidh.org/demandas/12.057\%20Almonacid\%20Arellano\%20Chile\%20 11jul2005\%20ESP.pdf

- GÁZQUEZ, María Yanina (2018): "El principio de razonabilidad en la cobertura de las prestaciones de salud", Revista Derecho y Salud UBP, Nro. 2,

- PALACIO DE CAERIO, Silvia B. (2015): Tratado de Derechos Humanos y su influencia en el derecho argentino, 1ra ed. Ciudad Autónoma de Buenos Aires, La Ley.

- ROSALES, Pablo Oscar: "La Discapacidad en el Sistema de Obras Sociales Nacionales, la Emergencia Sanitaria y los derechos de los beneficiarios con discapacidad"v https:// es.scribd.com/doc/63600339/Ley-24901-LA-DISCAPACIDAD-EN-EL-SISTEMA-DEOBRAS-SOCIALES-NACIONALES-Dr-Pablo-Oscar-Rosales 